\title{
MENGENAL SISTEMATIC REVIEW THEORY DAN STUDI KASUS
}

\author{
Rr. Tutik Sri Hariyati ${ }^{1 *}$
}

1. Dasar Keperawatan dan Keperawatan Dasar Fakultas Ilmu Keperawatan Universitas Indonesia, Depok 16424, Indonesia

*Email:rrtutik@yahoo.com,tutik@ui.ac.id

\begin{abstract}
Abstrak
Systematc Review merupakan salah satu metode yang menggunakan review, telaah, evaluasi terstruktur, pengklasifikasian, dan pengkategorian dari evidence based-evidence based yang telah dihasilkan sebelumnya. Langkah dan strategi pelaksanaan systematic review sangat terencana dan terstruktur sehingga metode ini sangat berbeda dengan metode yang hanya sekedar untuk menyampaikan studi literatur. Studi systematic review ini sangat relevan untuk digunakan oleh dunia keperawatan sebagai dasar preleminari study, untuk agenda riset di masa datang dan juga sebagai salah satu kajian yang dapat memberikan masukan terhadap perencanaan dan implementasi praktek keperawatan.
\end{abstract}

Kata kunci: evidence based, keperawatan, systematic review

\section{Abstract}

Systematic Review is one method that uses to the review, examination, structured evaluation, classification, and categorization of the evidence based that has been generated previously. Measures and implementation strategies systematic review is planned and structured so that the method is very different from the methods just to convey study literature. Study of this systematic review is highly relevant for use by the world of nursing as a basis preliminary studies, for the research agendas and also as one of the studies that can provide input to the planning and implementation of nursing practice.

Keywords: evidence based, nursing, systematic review

\section{Pendahuluan}

Pernahkah kita berfikir tentang berapa banyak artikel dan manuskrip telah dihasilkan sejak mulai abad ke20? Mungkin sudah banyak sekali tulisan baik hasil pemikiran maupun hasil riset yang sudah dipublikasikan maupun yang belum dipublikasikan. Artikel maupun tulisan hasil pemikiran ini akan tidak banyak bermanfaat dan memberikan informasi jika tidak dimanfaatkan untuk perkembangan ilmu pengetahuan di masa kini dan masa mendatang. Salah satu teknik untuk mengetahui evidence base dan menggunakan artikelartikel tersebut sebagai informasi adalah teknik systematic review. Pada bahasan ini penulis akan menyampaikan definisi, tujuan, langkah-langkah dalam penyusunan systematic review, jenis systematic review, serta studi kasus systematic review.

\section{Definisi Systematic Review}

Banyak istilah terkait dengan systematic review, antara lain kita kenal adanya integrative literature.
Integrative literature dikenal sebagai metode yang menggabungkan banyak studi orisinil. Ada dua jenis integrative literature yaitu literature review (review artikel atau state of the art review) dan systematic review. Apabila dalam systematic review dilakukan analisis statistik formal maka systematic review disebut meta analisis (Sastroasmoro \& Ismael, 2008).

Ada hal yang membedakan literature review dan systematic review, dimana pada literature review umumnya penelusurannya tidak dilaksanakan dengan sistematik, tidak diklasifikasikan dengan kriteria yang sebelumnya ditetapkan serta kurang dilaksanakan telaah kritis serta kurang dilaksanakan evaluasi sistematis terhadap kualitas artikel.

Systematic review mempunyai kriteria dimana penelaahan terhadap artikel dilaksanakan secara terstruktur dan terencana. Systematic review meningkatkan kedalaman dalam mereview dan membuat rigkasan dalam evidence riset (Davies \& Crombie, 2009). 


\section{Tujuan Systematic Review}

Tujuan sistematic review antara lain menjawab pertanyaan secara spesifik, relevan dan terfokus. Systematic review juga menjari hasil riset, menurunkan bias dari review, mensintesis hasil, mengidentifikasi gab dari riset (Torgerson, 2003). Systematic review juga sering dibutuhkan untuk penentuan agenda riset, sebagai bagian dari desertasi atau tesis serta merupakan bagian yang melengkapi pengajuan hibah riset (Davies \& Crombie, 2009).

\section{Langkah dalam Systematic Review}

Pelaksanaan Systematic Review mempunyai tahapan:

a. Mendefinisikan tujuan dari review dan menetapkan tipe dari evidence yang akan membantu menjawab tujuan review.

b. Pencarian Literatur. Pencarian literatur telah ditetapkan strateginya, apakah hanya literatur yang sudah terpublikasi ataukah termasuk laporan riset yang tidak terpublikasi. Tahun terbit juga ditetapkan batasannya. Penggunaan jenis bahasa (English dan non English), dan juga jenis literatur juga menjadi kriteria systematik review. Jenis literatur sudah ditetapkan sebelumnya yaitu apakah hanya berupa jurnal ataukah termasuk conference prociding, opini ataupun laporan projek. Cara penelusuran secara elektronik, search engines, databases dan websites ataukah pencarian secara manual juga ditetapkan sebelum pelaksanaan sistematik review.

c. Penilaian study. Penetapan kriteria inklusitermasuk jenis methodology apakah hanya yang kuantitatif ataukah termasuk riset kualitatif.

d. Mengkombinasikan Hasil. Hasil review setelah dilaksanakan harus dikelompokkan untuk mendapatkan makna. Penemuan agregration/ pengelompokan ini sering disebut evidence sinstesis.

e. Menetapkan hasil, penemuan dari penglompokan yag telah dilaksanakan perlu didiskusikan untuk menyimpulan konteks/ hasil review.

\section{Jenis-jenis Systematic Review}

\section{a. Rapid Evidence Assesment Review (REA)} Merupakan metode pencarian dan evaluasi literature secara cepat tetapi tahapan dan comprehensive dari review masih sangat terbatas.

\section{b. User Involvement}

Metode pencarian dan evaluasi literatur yang digunakan sebagai persyaratan dalam studi awal riset

\section{c. Mixed methods}

Metode pencarian dan evaluasi literature dengan metode blended yaitu menggunakan kriteria dilaksanakan baik pada riset dengan desain kualitatif muapun kuantitatif. Keuntungan mixed methods akan meningkatkan integritas dari hasil, tetapi kelemahannya adalah ketika ada kategorikal yang belum masuk dalam kriteria review.

\section{Studi Kasus}

Gambaran teori systematic review mungkin kurang menjelaskan dan sulit dipahami tanpa adanya contoh kasus. Berikut akan disampaikan satu contoh systematic review secara komprehensif dari evidence dari suatu jurnal dengan judul, "Comprehensive systematic review of evidence on developing and sustaining nursing leadership that foster a healthy work environment in health care".

Tabel 1. Hasil dari Trawl of Leadership Literature

\begin{tabular}{ll}
\hline Autonomy & Behavior \\
Champion & Clinical leadership \\
Conflict & Decision \\
Emotional Intelegence & Gobernance \\
Leadership & Leadership development \\
Manager & Mentor \\
Nursing Leadership power/empowerment & Syles \\
Supervision & Traits \\
\hline
\end{tabular}




\section{Evidence Review}

Merupakan kerjasama tim dari The Registered Nurses association of Ontario (RNAO) dengan Health Canada, Office of Nursning Policy (HC ONP) dan The Joanna Briggs Institute (JBI). Evidenced review terdiri dari 2 komponen yaitu luasnya skope dari literatur yang digunakan untuk proses pengembangan dan berfokus pada sistematik review yang komprehensif.

\section{Skope dari Literatur/ The Literature Trawl}

Literatur diperoleh dengan kata kunci yang berhubungan dengan kepemimpinan dengan pencarian menggunakan databases: CINAHL, MEDLINE, Embase, dan Psychinfo.

Tujuan dalam pencarian kata kunci adalah untuk menggambarkan seberapa luas literatur kepemimpinan yang sudah dipublikasikan untuk membantu expert panel dalam mereview pertanyaan atau dalam pengembangan protokol review terkait kepemimpinan dalam keperawatan.

Istilah-istilah yang digunakan yang menggambarkan kepemimpinan/leadership dalam keperawatan yang ditemukan dalam literatur disampaikan dalam tabel 1 .

\section{Review Sistematik secara Komprehensif}

Berfokus pada review sistematik secara komprehensif tentang pengembangan dan keberlanjutan dari kepemimpinan, dengan mengidentifikasi evidenced dari atribut dari kepemimpinan yang membantu meningkatkan lingkungan kerja yang sehat dan dampak perkembangan dari kepemimpinan.

Metodologis yang digunakan adalah System for Unified Management, Assesment and Review oF information (SUMARI) package. SUMARI adalah pengembangan dari software yang dikembangkan untuk membantu tenaga kesehatan, peneliti dan praktisi untuk sistematis review dengan kelayakan, arti, dan keefektifan serta evaluasi ekonomis dari kegiatan dan intervensi Feasibility, appropriatenessm meaningfulness, and effectiveness (FAME) scale.

\section{Protokol Systematic Review}

Tujuan umum review: untuk mengkaji kelayakan, arti dan keefektifan dari atribut kepemimpinan dalam keperawatan (pengetahuan, ketrampilan, kompetensi, tugas, sikap, karakteristik, tipe kepemimpinan, dan kebiasaan) dan dampak dari pengembangan dan kebersinambungan dari kepemimpinan keperawatan dalam membantu lingkungan kerja yang sehat.

Tabel 2. Mean, SD, and Frequencies of Demographic Characteristic of Subjects

\begin{tabular}{lcr}
\hline \multicolumn{1}{c}{ Variable } & SCU (n=34) & $\begin{array}{c}\text { ICUs (n= 109) } \\
\text { Mean } \pm \text { SD (range) }\end{array}$ \\
\hline Age & $35.9 \pm 7.0(26-55)$ & $29.5 \pm 5.7(22-49)$ \\
Years of nursing practice & $12.0 \pm 5.6(5-26)$ & $4.5 \pm 3.8(0.3-22)$ \\
Clinical care experience & $9.2 \pm 5.6(0.2-25)$ & $3.2 \pm 2.9(0.3-17)$ \\
Tenure at hospital & $6.0 \pm 1.0(0.2-2)$ & $3.7 \pm 3.0(0.3-18)$ \\
Tenure in present unit & $1.4 \pm 1.0(0.2-2)$ & $2.4 \pm 2.6(0.3-17)$ \\
\hline & Frequency (\%) & Frequency (\%) \\
\hline Gender & & $20(18)$ \\
Male & $4(12)$ & $90(82)$ \\
Female & $20(88)$ & $10(9)$ \\
Highest education & & $79(72)$ \\
Advanced & $9(27)$ & $21(19)$ \\
BSN & $13(38)$ & $96(87)$ \\
AD/ Diploma & $12(35)$ & $14(13)$ \\
Employment status & & $22(65)$ \\
Full time & $12(35)$ & \\
Part time & & \\
\hline
\end{tabular}




\section{Kriteria Inklusi}

Review terdiri dari kuantitaf dan kualitatif riset terkait kelayakan, arti dan keefektifan dari pengembangan dan keberlanjutan kepemimpinan keperawatan untuk membatu lingkungan kerja yang sehat untuk pelayanan kesehatan. Paper dengan level tinggi (level 1-2), termasuk meta-analisis, Random Clinical Trial/RCT, quasi RCT, kohort, kasus kontrol, studi diskritif, studi korelasi, studi interpretive, studi kritik.

Strategi pencarian baik pada riset yang sudah dipublikasi atau yang belum, dan yang berbahasa Inggris. Awalnya pencarian melalui MEDLINE dan CINAHL, dan berikutnya dikembangkan pencarian key word dengan:

a. CINAHL (1982-2003)

b. MEDLINE (1996-2003)

c. Current Content Library (S/d Desember 2003)

d. Cochrane (s/d Desember 2003)

e. Psychoinfo (s/d Desember 2003)

f. Embase (s/d Desember 2003)

g. Social Science abstract (s/d Desember 2003)

h. Econ Lit (s/d Desember 2003)

i. ABI informk Global (s/d Desember 2003)

j. $\operatorname{ERIC}(\mathrm{s} / \mathrm{d}$ Desember 2003)

k. Dissertation abstract International

(s/d Desember 2003)

Pengumpulan data dan analisis data dilaksanakan pada studi dengan menggunakan pendekatan kuantitatif dan kualitatif. Data kuantitatif dengan menggunakan instrumen Cochrane Colaboration and the Centre for review and dessimination, sedangkan data kualitatif dengan analisis System for the Unified Management, Assessment and Review of Information/ SUMARI.

\section{Hasil Studi}

\section{Gambaran Studi}

Total paper yang telah direview adalah 116 paper yang diperoleh dari strategi pencarian, evaluasi, dan pengkajian metodologikal. Dari 116 paper, 72 artikel dikeluarkan dengan alasan tidak sejalan dengan tujuan studi, sehingga ada 44 paper yang ikut studi dengan rincian: 1 dengan jenis sistematik review, 2 artikel dengan studi eksperimen, 29 studi diskriptif-korelasi, 5 interpretasi dan kritik paper dan 7 teks paper.

\section{Pengelompokan/Agregasi Review}

Agregasi dari hasil review paper dengan desain kuantitatif dikelompokkan dalam kategori pendapat pemimpin, lingkungan kerja untuk pengembangan kepemimpinan, struktur organisasi untuk pengembangan kepemimpinan, atribut kepemimpinan, pemberdayaan dan gaya kepemimpinan.

\section{Agregasi Paper dengan Desain Kuantitaif}

Kategori Pendapat pemimpin

Hasil review paper terkait pendapat pemimpin sangat heterogen sehingga di akhir studi, metasisntesis tidak dapat dilaksanakan dan menyimpulkan pendapat leadership dalam keperawatan.

Tabel 3. Comparison of Satisfaction and Motivation between Intensive Care Unit (ICU) and Special Care Unit (SCU) Nurses

\begin{tabular}{lccccc}
\hline \multicolumn{1}{c}{ Variable } & \multicolumn{2}{c}{ SCU (n= 34) } & \multicolumn{2}{c}{ IC U (n= 109) } & F $^{*}$ \\
\hline General satisfaction & 15.2 & 4.2 & 15.2 & 3.4 & 0.63 \\
Specific satisfaction & & & & & \\
$\quad$ Pay satisfaction & 10.2 & $2.3^{*}$ & 9.2 & 3.1 & $5.13^{*}$ \\
Supervisory satisfaction & 15.0 & $4.4^{*}$ & 13.3 & 4.4 & $6.98^{*}$ \\
Social satisfaction & 17.0 & 2.3 & 16.9 & 2.1 & 0.01 \\
Security satisfaction & 10.8 & 2.1 & 10.9 & 2.3 & 0.18 \\
Total job satisfaction & 68.6 & $11.0^{*}$ & 65.6 & 10.8 & $4.20^{*}$ \\
Growth satisfaction & 22.0 & 3.9 & 21.3 & 3.7 & 2.60 \\
Internal work satisfaction & 24.3 & 3.1 & 24.1 & 2.9 & 0.65 \\
\hline
\end{tabular}

${ }^{*} \mathrm{p}<0,05 .{ }^{*} F$ scores after controlling for age. ${ }^{*}$ Total satisfaction is the sum of general satisfaction and four dimensions of specific satisfaction. 


\section{Kategori Lingkungan Kerja}

Studi dilakukan selama 4 tahun, dengan 143 reponden, dengan gambaran demografi sebagai tabel 2 yang meperlihatkan distribusi frekwensi dari usia, lama bekerja, jenis kelamin, latar belakang pendidikan dan kategori pekerjaan di RS.

Pada tabel 3 secara umum setelah dikontrol dengan usia kepuasan di SCU lebih tinggi daripada ICU tetapi tidak ada perbedaan yang bermakna. Pada kepuasan pada penghargaan, pengawasan, dan pekerjaan nilai rata-rata di ruang SCU lebih tinggi daripada di ruang ICU, dan terdapat perbedaan rata-rata kepuasan yang bermakna di ruang SCU dan ICU.

Pada tabel 4 menunjukan ada perbedaan persepsi terhadap lingkungan kerja di SCU dan ICU. Ratarata persepsi di ruang SCU setelah dikontrol dengan usia nilainya lebih tinggi bila dibandingkan dengan nilai di ruang ICU, dan terdapat perbedaan yang bermakna antara ruang SCU dan ICU

Struktur Organisasi untuk Pengembangan Kepemimpinan

Studi RCT untuk mengkaji efisiensi dan efektifitas dari proses konsultasi yang terdiri dari sesi perawatmanajer- konsultasi pertemuan pemecahan problem (dengan parsisipasi pengambilan keputusan) untuk pengembangan kepemimpinan. Hasilnya berupa moral staf, kualitas pelayanan dan status absen. Studi dilakuaan pada 310 bed RS di Ontario dengan 15 klinik, dengan 201 responden. Hasil pada kelompok intervensi terdapat peningkatan yang bermakna terhadap persepsi lingkungan kerja fokus pada kohesif dibandingkan kelompok kontrol (mean $=4,63$, SD 15,76 dan mean $-2,45$, SD 14.10, $p=0.003)$ konsisten dengan perubahan $\mathrm{p}=0.005$, perubahan $\mathrm{p}=0.02$, lebih tergantung pada otoritas 0.02 . Terkait kualitas pelayanan menunjukkan $80 \%$ pasien merasa nyaman.

\section{Atribut Leadership}

Dari 29 paper dengan studi deskriptif korelasional, yang banyak membahas tentang kepemimpinan dengan kenyamanan kerja, pemberdayaan, gaya kepemimpinan, leadership behavior dan karakteristiknya.

\section{Pemberdayaan}

Ada 11 paper yang membahas tentang pemberdayaan, di mana pembahasan banyak terkait jobstatisfaction, employee accountability, efektifitas, komitmen organisasi, kepercayaan dan job tension

\section{Gaya Kepemmimpinan}

Gaya kepemimpinan banyak dibahas dan dikaitkan dengan output berupa kepuasan kerja, kepuasan pasien, kualitas hidup pasien, efektifitas, sedangkan gaya kepemimpinan yang dilaksanakan adalah social, transformational, instrumental, partisipatori, konsultatif dan transaksional.

Tabel 4. Comparisons of Staff Perception and Preference of Work Environment between The Special Care Unit (SCU) and Intensive Care Unit Nurses after Controlling for Age

\begin{tabular}{lccccc}
\hline \multicolumn{1}{c}{ Variable } & \multicolumn{2}{c}{$\mathbf{S C U}(\mathbf{n}=\mathbf{3 4})$} & \multicolumn{2}{c}{ ICU (n= 109) } & $\mathbf{F}^{*}$ \\
\hline Mean & SD & Mean & SD & \\
\hline Perception total & 43.3 & 7.1 & 32.9 & 4.8 & $82.9^{*}$ \\
Perception of work technology & 16.3 & 2.0 & 11.8 & 2.2 & $93.0^{*}$ \\
Perception of practice model & 18.2 & 4.4 & 15.3 & 2.9 & $19.4^{*}$ \\
Perception of management model & 8.5 & 2.3 & 5.6 & 1.6 & $53.0^{*}$ \\
Preference total & 35.4 & 4.0 & 34.4 & 3.9 & $9.62^{*}$ \\
Preference total of work technology & 10.2 & 1.5 & 9.9 & 1.4 & $6.9^{*}$ \\
Preference total of practice model & 9.6 & 1.3 & 10.0 & 1.2 & 0.00 \\
Preference total of management model & 15.6 & 2.5 & 14.4 & 2.6 & $8.8^{*}$ \\
\hline
\end{tabular}

${ }^{*} \mathrm{p}<0,05 .{ }^{*} F$ scores after controlling for age 


\section{Kualitatif Evidence}

Langkah-langkah yang diambil dalam agregasi data kualitatif adalah dengan menerjermahkan tema, metaphors atau konsep, mentranfer aktual teks atau ringkasan teks pada ilustrasi tema, metaphors atau konsep dan me- rekategorisasi data untuk memperoleh suatu sintesa. Adapun kategori kunci terkait leadership disampaikan dalam tabel 7.

Kategorisasi dan sintesa dari agregrasi dari hasil review paper dengan desain kualitatif dikelompokkan dalam kategori kolaborasi, edukasi, emotional inteligency, iklim organisasi, peningkatan profesionalisme, bagaimana pemimpin meningkatkan profesional pada staf dan atribut kepemimpinan yang positif. Dicontohkan satu sintesis darikategori sintesis kolaborasi dalam skema 1 .

\section{Implikasi dari Praktek}

Hasil riset ini merekomendasikan pada praktek:

1. Perbedaan gaya kepemimpinan dapat memberikan outcome yang positif pada staf, pasien, dan lingkungan yang sehat.

2. Kombinasi dari gaya kepemimpinan dapat berkontribusi terhadap lingkungan kerja yang sehat.

3. Vasiasi karakteristik dan behavior pemimpin dapat memberikan outcome yang positif pada staf, pasien, dan lingkungan yang sehat.

4. Kombinasi dari atribut kepemimpinan dapat menciptakan lingkungan kerja yang sehat.

5. Pola struktur yang memperdayakan sub-ordinat/ staf dapat meningkatkan dan memberikan outcome yang positif pada staf, pasien, dan lingkungan yang sehat.

6. Hasil riset merekomendasikan pada riset selanjutnya untuk mengkaji hubungan gaya kepemimpinan, karakteristik dan out come, terrmasuk didalamnya kenyamanan, dan kegunaannya.

\section{Kesimpulan}

Sistematic review merupakan metode dalam melaksanakan review artikel dengan standar, kriteria, terstruktur dan direncanakan sebelum pelaksanaan sistesis artikel. Systematic review dapat digunakan sebagai studi awal dalam meningkatkan kedalaman penyiapan proposal dan pelaksanaan riset dan sebagai state of the art yang lebih komprehensif, atau sebagai studi tersendiri yang outputnya berupa kajian dan artikel. Systematic review dapat menjadi salah satu alternative metode penulisan artikel berdasarkan telaah artikel yang telah ada sebelumnya, dan systematic review tidak hanya sekedar mencari sumber literatur tetapi merupakan kajian yang terstruktur dan dengan perencanaan yang sempurna.

Hasil systematic review yang mampu mensintesis dari banyak hasil riset sebelumnya dapat digunakan untuk kajian kebijakan untuk melengkapi hasil, meningkatkan hasil atau untuk memperoleh hasil dan rekomendasi terhadap hasilyang belum diperoleh/ belum dilaksanakan. Hasil systemetic review juga dapat digunakan untuk saran tindak lanjut agenda riset dan menyumbang rekomendasi pelaksanaan kebijakan (SS, YR, HR).

\section{Referensi}

Davies, T.H., \& Crombie, K. (2009). What is a systematic review. Hayward: Hayward Group Ltd.

Pearson, A., et al. (2007). Comprehensive systematic review of evidence on developing and sustaining nursing leadership that fosters a healthy work environment in healthcare. Systematic ReviewsJoanna Briggs Institute, 208-253. (Doi: 1456211501).

Sastroasmoro, S., \& Ismael, S. (2008). Dasar-dasar metodologi penelitian klinis. Jakarta: Sagung Seto.

Torgerson C. (2003). Sistematic review. London: International Publishing Group. 
Tabel 5. Positive Relationships between Empowerment and Outcomes

\begin{tabular}{|c|c|c|c|c|}
\hline Outcomes & \multicolumn{4}{|c|}{ Empower ment } \\
\hline Job satisfaction & $\begin{array}{l}\text { Laschinger }^{6} \\
\text { Manojtovich }^{7} \\
\text { Laschinger }^{8} \\
\text { Laschinger }^{9} \\
\text { Laschinger }^{10} \\
\text { Upi enieks }^{11}\end{array}$ & & & \\
\hline $\begin{array}{l}\text { Employee accountability } \\
\text { Work effectiveness }\end{array}$ & & & $\begin{array}{l}\text { Laschinger }{ }^{12} \\
\text { Laschinger }^{12} \\
\text { Laschinger }^{13}\end{array}$ & \\
\hline $\begin{array}{l}\text { Organizational commitment } \\
\text { Trust }\end{array}$ & & $\begin{array}{l}\text { Laschinger }^{9} \\
\text { Laschinger }^{9} \\
\text { Laschinger }^{14}\end{array}$ & & \\
\hline Job tension & & & & Las chinger $^{13}$ \\
\hline
\end{tabular}

Tabel 6. Positive relationships between Leadership Styles and Outcomes

\begin{tabular}{|c|c|c|c|c|c|c|}
\hline \multirow{2}{*}{ Outcomes } & \multicolumn{6}{|c|}{ Emp ow erment } \\
\hline & Social & Transfor mational & Instrumental & Participatory & Con sultative & Transactional \\
\hline $\begin{array}{l}\text { Fewer health complains } \\
\text { Job satisfaction }\end{array}$ & $\begin{array}{l}\text { Boumans }{ }^{15} \\
\text { Boumans }^{15}\end{array}$ & $\begin{array}{l}\text { Medley }^{16} \\
\text { Altieri }^{17} \\
\text { Stordeur }^{18}\end{array}$ & Boumans ${ }^{15}$ & & & \\
\hline $\begin{array}{l}\text { Lower staff turnover } \\
\text { Meaningfulness }\end{array}$ & Boumans $^{15}$ & & & Volk $^{19}$ & & \\
\hline Organization culture & & Corrigan $^{20}$ & & & & \\
\hline Patient quality of life & & Corrigan $^{21}$ & & Robertson ${ }^{22}$ & Robertson $^{22}$ & Corrigan $^{21}$ \\
\hline Patient satisfaction & & Corrigan $^{21}$ & & & & \\
\hline Staff extra effort & & $\begin{array}{l}\text { Altieri }{ }^{17} \\
\text { Stordeur } \\
\text { Dunham-Taylor }\end{array}$ & & & & \\
\hline Unit effectiveness & & $\begin{array}{l}\text { Altieri }^{17} \\
\text { Stordeur }^{18}\end{array}$ & & & & \\
\hline
\end{tabular}

Hargailah segala yang kau miliki; Anda akan memiliki lebih lagi.

Jika Anda fokus pada apa yang tidak Anda miliki, Anda tidak akan pernah merasa cukup dalam hal apapun.

- Oprah Winfrey - 
Tabel 7. Kategori kunci leadership

\begin{tabular}{|c|c|}
\hline No & Pene muan \\
\hline 1 & $\begin{array}{l}\text { Semua pemimpin memandang positif terkait peran di masa datang, mempunyai inovasi, kualitas pelayanan } \\
\text { pasien, self direction dan komponen peran dari Clinical Nurse Specialis/CNS }\end{array}$ \\
\hline 2 & Penting adanya persiapan dan pengetahuan yang berkelanjutan yang selalu di updated \\
\hline 3 & CNS merasa moti vasi turun jika tidak mendapat dukungan dari organisasi \\
\hline 4 & CNS merasa kendala dalam peran CNS adalah manajemen waktu \\
\hline 5 & Harapan yang tidak realistik dan multifokus membuat stres, frustasi \\
\hline 6 & Supervis or diga mbarkan merupakan peran yang menyiapkan struktur dan mensuport \\
\hline 7 & Pemimpin adalah seseorang yang respek pada perke mbangan personaliti staf \\
\hline 8 & Respek dan mendengarkan staf adalah penting bagi pemimpin \\
\hline 9 & Pemimpin merasakan apa yang dirasakan staf \\
\hline 10 & $\begin{array}{l}\text { Ideal dari staf adalah mempunyai beberapa pengetahuan terkait nursing, psikologi, filosofi, proses grup, human } \\
\text { dan pengembangan moral }\end{array}$ \\
\hline 11 & Ideal supervisor yang mempunyai jiwa kepemimpinan yang besar \\
\hline 12 & Respon pada staf merupakan positif dari pemimpin \\
\hline 13 & Personal dan pertumbuhan staf yang profesional dapat ditingkatkan melalui ga ya supervisi \\
\hline 14 & Ketrampilan dalam mendengar merupakan kualitas personaliti dari pemimpin \\
\hline 15 & Memperole pengetahuan teori dan pengalaman adala langkah untuk meningkatkan peran supervisor \\
\hline 16 & Pemimpin adalah seseorang yang mendengar, respek dan memberikan dukungan yang dibutuhkan oleh staf \\
\hline 17 & Pemimpin memperlihatkan sikap as ertif \\
\hline 18 & Persisten dari pemimpin dapat diperlihatkan untuk menjadi pemimpin yang efektif \\
\hline 19 & Staf menggambarkan pemimpin yang bersahabat, mendekat dan menyenangkan \\
\hline 20 & Staf keperawat an ingin pemimpin yang memberikan kesempatan perkembangan profesionalisme \\
\hline 21 & Pemimpin harus menanpi lkan kejujuran untuk membangun hubungan yang kuat dengan staf \\
\hline 22 & Pemimpin adalah yang yang memberikan aturan untuk mendapatkan hasil yang lebih efektif \\
\hline 23 & Elemen dari kepemimpinan adalah memberikan kesempatan dan jalan untuk perkembangan profesional \\
\hline 24 & Perawat lebih suka diberikan dukungan keputusan dengan informasi yang cukup \\
\hline 25 & Mempersiapkan staf untuk dapat memperoleh sumber untuk meningkatkan efektifitas kerja \\
\hline 26 & Organisasi memberikan dukungan lingkungan yang membantu peningkatan outcome pasien \\
\hline 27 & Kerjasama antar profesional kesehatan akan meningkatkan outcome \\
\hline 28 & Posisi pemimpin penting dalam meningkatkan lingkungan yang baik bagi staf \\
\hline 29 & Mentor kepada staf akan meningkatkan pertumbuhan profesional \\
\hline 30 & Pengetahuan dan sikap positif dari pemimpin adalah bagian integral yang mempengaruhi retensi staf \\
\hline 31 & Pemimpin adalah seseorang yang menciptakan lingkungan positif untuk kenyamanan dan kebetahan dari kerja \\
\hline 32 & $\begin{array}{l}\text { Pengertian terdap kunci dimensi: fleksibel, responsibilioti, standar, reward, clarity, komitmen tim membantu } \\
\text { untuk mengert ikl im organisasi dan membantu pemimpin dalam menciptakan lingkungan yang positif }\end{array}$ \\
\hline 33 & $\begin{array}{l}\text { Kolaborasi dengan pimpinan perawat di level yang berbeda dapat menciptakan lingkungan yang sehat untuk staf } \\
\text { dan pasien }\end{array}$ \\
\hline
\end{tabular}


Lanjutan Tabel 7. Kategori kunci leadership

\begin{tabular}{|c|c|}
\hline No. & Penemuan \\
\hline 34 & $\begin{array}{l}\text { Pendidikan dapat membantu mengembangkan kualitas yang diperlukan dalam menciptakan lingkungan yang } \\
\text { sehat }\end{array}$ \\
\hline 35 & Kolaborasi dengan tim medis dapat membantu outcome pasien dan keluarga yang positif \\
\hline 36 & Kolaborasi dengan interdisiplin membantu meningkatkan outcome pasien \\
\hline 37 & $\begin{array}{l}\text { Seseorang dengan peran pemimpin menggunakan emosional intelegensi untuk dampak yang positif, outcome } \\
\text { pasien }\end{array}$ \\
\hline 38 & $\begin{array}{l}\text { Pemimpin yang efektif dapat menampilkan karakteristik intelegensi emosional (memotivasi, komunikasi dan } \\
\text { mengorga nisasi manajemen konflik) }\end{array}$ \\
\hline 39 & $\begin{array}{l}\text { Organisasi dimana pemimpinnya menampilakan inteligensi emosional akan meningkatkan pencapaian } \\
\text { organisasi, staf dan pasien }\end{array}$ \\
\hline 40 & Pemimpin adalah seseorang yang memotivasi staf untuk meningkatkan outcome pasien \\
\hline 41 & Pemimpin menggunakan keputusan bersama untuk meningkatkan kenyamanan staf \\
\hline 42 & $\begin{array}{l}\text { Pemimpin menggunakan } 9 \text { kualitas dalam integrated leadership practice model (self-knowedge, respec, trust, } \\
\text { integrity, share vision, learning, partisipation, communication, change facilitator }\end{array}$ \\
\hline
\end{tabular}

Skema 1. Sintesis Kolaborasi

\section{Synthesis 1 - Collaboration \\ (a) Discursive evidence}

\section{Findings}

Collaboration with nursing leader from different levels can aid in the success of creating a he althy environment for staff and patients. (Finding 33) [C]

Collaboration with the medical team can assist in creating positive outcomes for patients and patient's families. (Finding 35) $[\mathrm{C}]$

The collaboration with interdisciplinary teams may be able to improve patient outcomes. (Fin ding 36) [C]

\section{(b) Qualitative evidence}

Findings

Collaboration among health professionals can results in improved outcomes. (Fin ding 27) [C]

\section{Category}

The collaboration of
nursing leaders can
improve the work
environment.

Staff and patient outcomes can improve when the healthcare team collaborates.

\section{Syn th esis}

Healthcare teams that collaborate can improve outcomes for staff and patients resulting in creating a healthier work environment.

Staff and patient
outcomes can improve
when the healthcare
team collaborates.

